\title{
CDISC SDTM Evaluator Terminology
}

National Cancer Institute

\section{Source}

National Cancer Institute. CDISC SDTM Evaluator Terminology. NCI Thesaurus. Code C78735.

Terminology associated with the evaluator codelist of the Clinical Data Interchange Standards Consortium (CDISC) Study Data Tabulation Model (SDT M). 